\title{
Terras Indígenas do Espírito Santo sob o Regime Territorial de $1850^{1}$
}

\author{
Vânia M aria Losada M oreira \\ Universidade Federal do Espírito Santo
}

\section{RESUM O}

N este artigo são analisados os direitos territoriais indígenas durante 0 século $X I X, 0$ impacto da Lei de Terras de 1850 sobre tais direitos, e o processo histórico-social de expulsão e de expropriação territorial, então em curso, contra as populações de índios do Espírito Santo (Tupiniquins, Puris e Botocudos).

Palavras-chave: terras indígenas; Lei de Terras de 1850; índios.

\section{ABStRACT}

In this article, I discuss the territorial rights of the indigenous population during the $19^{\text {th }}$ century, the impact of the Land Law of 1850 on such rights, and the historical and social process of territorial ouster and expropriation against the populations of Tupiniquim, Puri and Botocudo Indians.

Keywords: Indigenous people land; the Land Law of 1850; indians.

Os direitos territoriais representam, ainda hoje, um dos pontos centrais da pauta de reivindicação dos povos e comunidades indígenas do Brasil. A título de exemplo, basta revermos o documento elaborado pelos membros da "Conferência dos Povos I ndígenas", que reuniu cerca de 3.000 representantes de 140 povos indígenas, em Santa Cruz de Cabrália (BA), durante as comemorações que marcaram os "500 anos do Brasil", em 2000. No documento final redigido pelos conferencistas, pode-se verificar que a demarcação ea regularização de todas as terras indígenas e a retirada dos invasores ("desintrusão") figuram em lugar de destaque, ao lado de outras solicitações igualmente fundamentais: o fim de todas as formas de discriminação, a apuração dos crimes cometidos contra os povos indígenas nos últimos 20 anos e várias providências nas áreas da educação e da saúde².

Além das reivindicações formuladas pelos representantes indígenas reunidos em Cabrália,cabe mencionar outra questão não menos complexa e contundente, derivada, dentre outras condições, do fato de ainda prevalecer na sociedade brasileira uma visão esquemática sobre o que é ser efetivamente um índio ou uma comunidade indígena. Refiro-me à luta de várias comunidades no sentido de serem oficialmente reconhecidas como tendo origem ét- 
nica pré-colombiana,a despeito de não se amoldarem às imagens amplamente estabelecidas de primitividade ou do índio genérico. Esteéo caso, por exemplo, dos Caxixós (ou Kaxixós), do Capão do Zezinho (M G) , cujo reconhecimento oficial ainda está em processo de discussão eavaliação. Foi também um problema enfrentado pelos Tupiniquins do Espírito Santo, que conseguiram o reconhecimento da FUNAI e da sociedade regional,após longa luta para reafirmar a identidade étnica do grupo e preservar seus tradicionais territórios, ameaçados pela expansão comercial da produção de eucaliptos e por um discurso que lhes negava a ascendência indígena ${ }^{3}$.

No presente artigo, procuro discutir uma questão essencial para a sobrevivência das comunidad es indígenas já assi miladas ou em vias de assimilação durante 0 século XIX, mas que obteve pouca atenção das autoridades, permanecendo durante to do o Segundo Reinado como um assunto bastantecontrovertido e impreciso: a posse e a propriedade territorial indígena. Desnecessária se faz uma argumentação mais longa para demonstrar quanto são pertinentes e atuais as reflexões historiográficas sobre os problemas ter ritoriais enfrentados pelos índios ao longo do processo de desenvolvimento histórico do País. Uma compreensão mais vasta dos desafios que as comunidades indígenas ainda hoje enfrentam no campo de seus direitos territoriais passa, como acredito, por uma revisão histórica sobre os diferentes casos de assimilação social e de expulsão das comunidades indígenas de seus tradicionais territórios.

\section{PATRIM ÔNIO TERRITORIAL INDÍGENA}

A questão indígena durante o século XIX era complexa e muito mais abrangente do que o desafio representado pelo contato e pacificação dos grupos indígenas isolados e independentes que viviam nos sertões, pois,além dos povos então consider ados "selvagens", existiam outras tantas comunidades já integradas ao tecido so cial. No entanto, desde a publicação do Regulamento Acerca das M issões de Catechese e Civilização dos Índios, em 1845, a ação institucional ocupou-se fundamental mente do fomento de al deias e missões para "civilizar" e "catequizar" as chamadas "hordas selvagens" do País,dando pouca atenção a outros fatores que também afetavam ou poderiam ter impacto sobre a população indígena daquele período. Isso fica bastante evidente em relação aos direitos territoriais e patrimoniais dos índios, em que prevaleceu a simplificação, o descaso, e até mesmo a arbitrariedade.

Em maior ou menor extensão ou com mai or ou menor clareza, desde o período colonial, a política institucional em relação aos índios manteve-se 
indissociável da política territorial. Já no século XVII, a legislação portuguesa fornecia inequívocas provas da ligação entre essas duas políticas. O Alvará de 1 o de abril de 1680 foi absolutamente claro sobre a posse e os direitos dos indígenas em relação aos territórios que ocupassem, mesmo quando tais terre nos estivessem encravados em sesmarias concedidas. De acordo com a legislação de 1680, “( ... ) na concessão de sesmarias se reserva sempre o prejuízo de terceiros, e muito mais se entende, e quero que se entenda, ser reservado 0 prejuízo e direito dos índios, primários e naturais senhores dellas"4.

A correlação entre questão indígena e política territorial reaparece de forma inequívoca em todos os momentos importantes que marcaram a evolução da política indigenista.Esteve presente, desse modo, nas regulamentações pombalinas, que asseguram liberdade aos índios, mas igualmente a posse de seus bens e comércio. Ou ainda, na política de aldeamentos e no Regulamento das $\mathrm{M}$ issões, pois em ambos os casos se reservavam as terras das aldeias e missões ao uso e benefício dos índios aldeados.A rigor, inexistiu uma política indigenista que não envolvesse uma política de terras destinada aos índios, compreendida no cenário mais vasto da política territorial global de cada período histórico. Um dos resultados da evolução das políticas indigenistas e territoriais foi, obviamente, a produção de situações patrimoniais diversas entre os índios assimilados ou em processo de assimilação, condicionadas pelo momento histórico-social em queforam incorporados à sociedade dominante em expansão.

A situação patrimonial dos índios no Espírito Santo durante a primeira metade do século XIX é um testemunho da variedade de condições reais e legais historicamente produzidas em relação à terra. Depois da expulsão dos jesuítas em 1759-60, por exemplo, os índios da capitania, que eram sobretudo de origem Tupiniquim e Temiminó, receberam sesmarias (o caso dos índios da M issão de Reritiba) ou tiveram suas sesmarias confirmadas ( o caso dos índios da M issão dos Reis M agos). Do ponto de vista legal,tais índios tornaram-se, por direito, possuidores de sesmarias. Já os Puris e Botocu dos, incorporados à sociedade local sobretudo a partir de 1800, foram reunidos em aldeamentos e agraciados com as terras das aldeias. O s índios das tribos independentes estavam em situação relativamente nebulosa. Poderiam ser considerados como os primeiros ocupantes da terra e, portanto, portadores de direito primário e originário sobreela. No mínimo e na pior das hipóteses,as tribos independentes tinham por direito pelo menos as terras dos aldeamentos que deveriam ser fundados para eles.

Do ponto de vista real, no entanto, embora os índios pudessem encontrar na legislação fundamentos para garantir seus direitos sobre os territórios que ocupavam, a tendência geral foi o contínuo avanço sobre seus territórios 
e, por fim, a expulsão. Pouco mais de cinqüenta anos depois da saí da dos padres jesuítas, as terras das sesmarias indígenas do Espírito Santo eram alvo de invasões e expropriações, inclusive com o aval dos administradores locais. Quando o natural ista Saint-H ilaire esteve no Espírito Santo, em 1818, ele observou que a sesmaria indígena de Benevente (antiga M issão de Reritiba) estava sendo ocupada de diversas formas por luso-brasilei ros: graças às doações feitas pelos governadores aos seus amigos; por meio de pequenas contribuições pagas à municipalidade para o uso de terras que índios cediam para poderem comprar aguardente; pela simples posse ilegal e, finalmente, em virtude da distribuição oficial de sesmarias nas terras indígenas ${ }^{5}$. Em todos esses casos, como observou Saint-H ilaire, tratava-se de procedimentos ilegais, que desrespeitavam abertamente os direitos territoriais indígenas.

A observância e garantia dos direitos indígenas ficavam a cargo dos administradores e juízes locais, mas esses setores dirigentes muito raramente defenderam os direitos e as posses dos índios. A esse respeito, Saint-Hilaire salientou:

Quando o índio pede justiça contra o português, como poderá obtêla? É aos amigos e patrícios de seus adversários que ele é obrigado a dirigi r-se, já que os juízes ordinários de Benevente são exclusivamente portugueses.E, ainda, como as queixas de uma raça de homens pobres e sem apoio chegarão até os magistrados superiores, a tão grande distância desses infelizes e, na maioria das vezes, surdos à voz dos que se apresentam de mãos vazias?

0 destino das terras da antiga M issão dos Reis M agos, transformada após a expulsão dos jesuítas na vila de N ova Almeida, encontrava-se em situação um pouco melhor. Do ponto de vista de Saint-Hilaire, duas razões explicavam a melhor sorte daquel es índios. Primeiro, o distrito ainda era administrado, por ocasião de sua viagem, por uma ampla maioria de índios. A aldeia era dirigida, desse modo, por um capitão indígena e possuía dois juízes que se alternavam, sendo um deles índio. A câmara era composta totalmente por índios, exceção feita ao provedor ${ }^{7}$. Esta situação administrativa mais favorável aos direitos e interesses indígenas fez com que os luso-brasileiros estabelecidos em terras da sesmaria pagassem aforamento e tivessem apenas o direito de vender suas colheitas e benfeitorias, permanecendo a terra sob 0 controle da Câmara. Segundo, Nova AImei da localizava-se em região menos fértil e não estava, ainda, na rota de expansão agrícol a da sociedade local. Entretanto, ainda como observou Saint-Hilaire, tal conjuntura que favorecia grandemente os índios de Nova Almeida era absolutamente provisória, pois 
(... ) aqui houve pouca oportunidade de violar os direitos dos indígenas, porque a região não apresenta, por assim dizer, qualquer atrativo à cobiça: émenos fértil,isolada, vizinha dos botocudos; nela as formigas causam contínuos estragos; por fim, o Rio dos Reis Magos pouco oferece em pequenos recursos de transporte ${ }^{8}$.

O progressivo desenvolvimento deNovaAlmeida demonstrou,aliás, quanto as previsões de Saint-H ilaire estavam corretas. Em 1848, foi tirado da Câmara M unicipal de Nova Almeida o rendimento dos forose ainda, no mesmo ano, boa parte da população, das terras e das economias da Câmara foram destinadas à criação da vila de Santa Cruz. Em 1852, mais uma vez, Nova Almeida foi atingida por medidas políticas que enfraqueciam a municipalidade, pois perdia nova porção do seu território, então cedido à vila da Serra.Finalmente, perdeu também a autonomia administrativa, pois a partir de 1853 passou a subordinar-se à vila da Serra. Tal foi o destino da antiga M issão jesuítica, que Cezar Augusto Marques,escrevendo em 1878, observou:“Parece que havia tenção firme ou capricho em apressar a ruína desta vila" ${ }^{\text {. }}$

A desorganização sociocultural das aldeias indígenas de Reritiba e de Nova Almeida era uma decorrência da expansão da fronteira agrícola e da intervenção política dos dirigentes sobre aquelas populações e localidades. No caso específico de Benevente, as críticas de Saint-Hilaire dirigiam-se simultaneamente contra a Câmara M unicipal, o governo da capitania e o sistema judiciário, pois todos agiam em detrimento dos interesses indígenas. Já no caso de N ova Almeida, o naturalista eximiu de qualquer responsabilidade a Câmara M unicipal, uma vez que, na maioria, seus membros eram índios, quea posse indígena sobre a terra estava protegi da e que os foros cobrados revertiam para o bem da Câmara Municipal. Desse modo, em 1818, as terras indígenas de Beneventejá eram um objeto de disputa que envolvia, entre outros setores, índios, fazendeiros, Câmara M unicipal e governo regional, enquanto em N ova Almei da as terras estavam sob controle não propriamente dos índios, mas da Câmara Municipal, cuja maioria era indígena.

As perdas de território sofridas pelos índios de Benevente e N ova Almeida durante o início do século XIX significaram, em primeiro lugar, que seus títulos de sesmeiros estavam sendo ignorados. 0 processo de expulsão tornouse ainda mais complexo nos anos seguintes, não apenas porque o regimefundiário sofreu profundas modificações, mas também porque foi intensificado 0 processo de incorporação de novas terras ao sistema produtivo. Em ambos os casos, o direito indígena sobre as terras foi profundamenteignorado.

Entre 1822 e 1850, interval o entre a suspensão do Regime de Sesmarias ea edição da Lei de Terra, o Brasil desenvolveu-se sob a ausência de uma le- 
gislação reguladora do processo de apropriação territorial e, em conseqüência, a posse se tornou a forma mais usual de aquisição de terras. A nova conjuntura favoreceu o desenvolvimento de grupos locais que deixaram de encontrar limitações legais ao processo de apropriação territorial.Estava sendo plantada a semente que daria origem, posteriormente, à classe dos grandes proprietários rurais brasileiros.

A suspensão do Regimede Sesmarias não significou que os antigos sesmeiros tivessem perdido os direitos anteriormente adquiridos. Nem tampouco que a concessão de sesmarias tivesse sido revogada em toda e qualquer circunstância. 0 decreto imperial n. 102 de 5/5/1824 explicava, por exemplo, que só se podia conceder sesmarias nas margens do rio Doce espírito-santense, e não em toda a província ${ }^{10}$. E, de fato, mesmo depois da suspensão do antigo regime fundiário, o governo local continuou o processo de distribuição de sesmarias no vale do rio Doce até o início dos anos 30, pois o objetivo a ser al cançado com tais concessões era,segu ndo a visão oficial, facilitar a ocupação sub-regional e a "civilização" dos "índios selvagens". M as fora de regiões específicas e consideradas merecedoras de incentivo especial à colonização, 0 regime de sesmarias foi abolido.

\section{A LeI de Terras de 1850 e a Questão Indígena}

Com a promulgação da Lei de Terras (Lei n. 601, de 18/9/1850), a continuidade de formação de novas posses foi expressamente proibida. A partir de então, todos os interessados em novas terras deveriam adquiri-las de forma legal, ou seja, por via da compra. M as a nova lei e suas regulamentações de 1854 igualmente abriram caminho para a legitimação de antigas posses e sesmarias, isto é, anteriores a 1850. A legal ização territorial foi importante sobretudo para os possei ros de mai or porte que transitaram dessa condição para o patamar de uma classe social cujo traço distintivo passou a ser a grande propriedade rural. Para eles, a nova legislação significou obter o reconhecimento jurídico de um status social anteriormente adquirido ${ }^{11}$.

Defundamental importância,a nova legislação tentou separar claramente os domínios privados dos outros ainda não apropriados, que passariam a formar os domínios pertencentes ao poder público. No processo de legitimação e revalidação de posses e sesmarias, optou-se pelo procedimento simplificado do processo administrativo, uma alternativa que passava ao largo da justiça. Como observou Lígia O sório Silva, a magistratura era uma das instituições mais organizadas do período, e o fato de ter sido deslocada do processo de reorganização da nova estrutura fundiária é bastante significativo, 
pois sugere uma vitória das oligarquias regionais, que não simpatizavam com a centralização administrativa ${ }^{12}$.

A partir da nova lei,passaram a existir as terras do domínio privado, que deveriam ser legitimadas ou revalidadas, eas terras do domínio público, que deveriam ser demarcadas. As terras do domínio público eram compostas pelas então consideradas terras devolutas. 0 termo "devoluto" perdeu, contudo, o seu sentido inicial. De terras doadas ou apropriadas que, por não terem sido aproveitadas, eram devolvidas ao senhor original, isto é, ao rei, o conceito passou a designar as terras não apropriadas ou públicas ou, dito de outra forma, vagas ${ }^{13}$. Todavia,a interpretação da letra da lei jamaisfoi unívoca,e o conceito de devoluto gerou especulações de várias ordens.

Qu estões como a legitimação de uma sesmaria podiam gerar interpretações antagônicas. Por exemplo, as sesmarias incultas deveriam ser consideradas como terra devoluta ou serem legitimadas como propriedade do antigo sesmeiro? As terras indígenas eram devolutas ou, ao contrário, sobre os territórios ocupados por eles ainda era válido o "direito originário"? Longe de de finirem um conceito claro e inequívoco para o vocábulo devoluto, senadores e deputados criaram uma lei onde devoluto definiu-se por exclusão. De acordo com o artigo terceiro da nova lei, eram devolutas as terras nas seguintes condições:

Parágrafo 10 : As que não se acharem aplicadas a algum uso público nacional, provincial ou municipal.

Parágrafo 2o: As que não se acharem no domínio particular por qualquer título legítimo, nem forem havidas por sesmarias e outras concessões do Governo Geral Provincial, não incursas em comisso por falta do cumprimento das condições de medição, confirmação e cultura.

Parágrafo 3o: As que não se acharem dadas por sesmarias, ou outras concessões do governo, que apesar de incursas em comisso, forem revalidadas por esta lei.

Parágrafo 40: As que não se acharem ocupadas por posse, que apesar de não se fundarem em título legal, forem legitimadas por essa lei ${ }^{14}$.

Para alguns juristas, o espírito da lei baseava-sena idéia geral de garantir-se a propriedade territorial àqueles que efetivamente cultivavam a terra, independentemente da posse legal ou não. Sublinhavam, ademais, que a nova legislação corroborava um dos princípios fundamentais do antigo Regime de Sesmarias, cujas vali dações das concessões de terra dependiam de efetiva cultura e morada habitual. Parecia óbvio, portanto, considerar como devolutas as sesmarias incultas e sem morada habitual. M as, de acordo com outros, a Lei deTerras, em seu artigo terceiro, excluía da definição de terras devolutas 
aquel as que se achassem no domínio particular por qualquer título legítimo. Teoricamente, portanto, mesmos as sesmarias incultas poderiam ser legitimadas, já que possuíam títulos legítimos. Além disso, não havia no corpo da lei nada que pudesse sugerir que devoluto tivesse por significado a idéia de terrenos incultos, ficando antes o termo "devoluto" estabelecido como "vago"15. Apesar da polêmica, segundo Lígia Osório Silva,

(... ) abandonou-se, com o tempo, a questão do cultivo como critério de definição para as terras devolutas. Aos poucos, terras devolutas passaram a ser: 1) as quenão estavam aplicadas a algum uso público nacional,estadual ou municipal;

2) as que não estavam no domínio particular, em virtude de título legítimo ${ }^{16}$.

$\mathrm{Na}$ Lei deTerras a questão indígena foi contemplada no artigo 12 , onde se podia ler que caberia ao governo reservar terras devolutas para a "colonização dos indígenas" ${ }^{17}$. I nexistia, na nova legislação, qualquer referência ao direito originário indígena sobre os territórios que tradicionalmente ocupavam,isto é, sobre o "indigenato". M endes Júnior, comentando a Lei de Terras de 1850,argumentou, em 1912, que a relação do índio com a terra era de "domínio imediato", “congênito”, isto é,um "direito originário", reconhecido, aliás, pela legislação portuguesa do período colonial. Para ele, "o indigenato não é um facto dependente de legitimação, ao passo que a ocupação, como facto posterior, depende de requisitos que a legitimem"18.

Prosseguindo sua argumentação, M endes Júnior sublinhou que a regulamentação da Lei de Terras de 1854, Art. 24,§ 1, li berou os indígenas de qualquer necessidade de legitimarem suas terras, já que apenas estavam sujeitos à legitimação " (... ) as posses que se acham em poder de primeiro ocupante, não tendo outro título senão a sua ocupação". Para M endes Júnior, essa passagem da regulamentação da nova lei territorial reconhecia a existência de primeiro ocupante quetinha título diverso da ocupação, e, como el e mesmo escreveu: "E qual pode ser esse primei ro ocupante, com título distinto da sua ocupação senão o indígena, aquelle que tem por titulo o indigenato, isto é, a posse aborígine?" ${ }^{19} \mathrm{O}$ próprio M endes Júnior reconheceu, no entanto, que a interpretação da Lei deTerras por ele realizada, a partir da qual ficou reconhecido o direito originário dos índios sobre as terras que ocupavam, se fez pela "dedução" da própria lei. A lei, de fato, não mencionou o indigenato e, por isso, viabilizava toda sorte de interpretações.

Reflexo da imprecisão da nova lei em relação aos direitos indígenas são as opiniões mais recentes dos pesquisadores, que ainda divergem bastante entre si. JoséM auro Gagliardi avaliou, por exemplo, que com a nova lei “( ... ) o indígena passou da condição de proprietário natural da terra à condição de 
expropriado ea depender da benevolência do Estado para ter algo que um dia Ihe pertenceu"20. Já na visão de M anuela Carneiro, a questão é mais complexa, pois as terras indígenas não poderiam ser consideradas como devolutas, em função do direito originário dos índios sobre os ter ritórios que ocupavam² ${ }^{21}$. Entretanto, para além da discussão teórica que ainda hoje vigora sobre o sentido da lei, é importante, do ponto de vista histórico, conjugar a reflexão sobre o sentido da legislação com sua aplicação prática, pois é nessa interseção que podemos resgatar parte da experiência histórica dos índios do período.

Pudessem ou não ser consideradas devolutas as terras ocupadas pel os índios, o fato é que a Lei de Terras simplificou as relações dos índios com a terra de maneira radical. Desse modo, a lei apenas previa a possibilidade de reservar terras à "colonização indígena", omitindo-se sobre o chamado direito originário esobre as terras indígenas que possuíam títulos legítimos. Na nova lei, o conceito de “indígenas" também estava longe de ser claro, mas não restam dúvidas de que por "indígenas" se compreendia aqueles indivídu os pertencentes às chamadas "hordas selvagens", tal como posteriormente ficou esclarecido na sua regulamentação, graças ao D ecreto n. 1368, de 30 de janei ro de 1854. Segundo o Art. 72: "Serão reservadas terras devolutas para a colonização e aldeamento deindígenas nos distritos onde existirem hordas selvagens."

Importante salientar que, em relação à questão indígena, a Lei de Terras e seus regulamentos corroboravam a perspectiva de uma outra legislação que Ihe antecedeu e que se voltava particularmente para a questão da "catequese e civilização" dosíndios ("selvagens"): o Regulamento das M issões, de 1845. A Lei de Terras, ao prever terras reservadas à colonização indígena, estava, na realidade, dando suporte ao Regulamento das $M$ issões que se propunha a tarefa de criar aldeias e missões para o assentamento dos índios.

A Lei deTerras era omissa em relação à figura do "índio civilizado", isto é, nada dizia, em particular, sobre os direitos de indivíduos ou comunidades integradas à ordem social dominante e que não poderiam ser, em hipótese alguma, ainda considerados como partes de tribos independentes. Isso significava que, do ponto de vista legal, o patrimônio territorial desses índios deveria ser legitimado nos mesmos termos propostos pela nova lei em relação às terras possuidoras de títulos legítimos. Em outras palavras, existiam sesmarias indígenas e terras de aldeias anteriores a 1850, todas protegidas por títulos legítimos que, deacordo com a nova lé, deveriam ser revalidadas e legitimadas. O caso do Espírito Santo ilustra essa situação. O síndios descendentes dos Tupiniquins/Temiminós, das antigas missões jesuíticas, tinham sesmarias demarcadas e confirmadas desde o período colonial, e uma das aldeias mais importantes da província, a M issão Imperial Affonsino (índios Puris), havia sido criada antes da lei de 1850. 
A existência das sesmarias e aldeias indígenas representava, contudo, um empecilho à expansão da sociedade nacional do período. Esta era, pelo menos, a opinião de M achado Nunes, presidente da província do Espírito Santo em 1855:

Formou-se a pouco no Rio de Janeiro uma companhia com o fim de empreender a colonização das terras do Rio Novo pertencentes aos municípios de Benevente e Itapemirim. N ão foi porém feliz nos seus primeiros passos, porque havendo na província abundância de excelentes terras que podem ser medidas sem contestação de posseiros ou sesmeiros,escol heu-se desgraçadamente as terras do Rio Novo, onde boas ou más, existem muitas posses, e até a sesmaria pertencente aos índios da antiga Reritiba (Benevente hoje) ${ }^{22}$.

É bastante compreensível a preocupação esboçada por M achado Nunes. A Lei de Terras e a regulamentação de 1854 foram bastante claras no sentido de orientar a colonização para as chamadas terras devolutas. Em outras palavras, deveriam ser evitados projetos de colonização em áreas de posses e sesmarias. Em tais regiões seria necessário, primeiro, realizar-se o processo de legitimações para,em um segundo momento, o governo começar a demarcação das chamadas terras devolutas. Só depois de efetivados esses dois procedimentos estariam aquelas áreas disponíveis à colonização e à venda, pois o objetivo era evitar que a criação de novos assentamentos cau sasse danos a terceiros ${ }^{23}$. A recomendação expressa nos regulamentos da lei, de iniciar a colonização em áreas incontestavelmente devolutas, dificultava o aproveitamento das terras devolutas encravadas em áreas de povoamento antigo. Isso porque era não apenas necessário esperar que primeiro fossem feitas todas as legitimações,mas também porque não cabia ao governo dar início ao processo de medições e legitimações.

A responsabilidade dos presidentes de província era exigir dos juízes de direito, dos juízes municipais, dos delegados, dos subdelegados e dos juízes de paz informações sobre a existência ou não de posses e sesmarias em suas comarcas, passíveis de serem legitimadas. Com tais informações, ainda era da responsabilidade do presidente da província a nomeação de juiz comissionário para cada município em que existissem casos de terras particulares a serem demarcadas e legitimadas. 0 juiz só entrava em ação, porém, a partir do requerimento dos particulares. A regulamentação da Lei de Terras impedia, portanto, que qualquer autoridade pública desencadeasse, por conta própria, o processo de legitimação ${ }^{24}$.

0 mesmo não acontecia em sub-regiões reconhecidamente devolutas, isto é, que não estivessem encravadas entre posses ou sesmarias. A demarcação 
dessas áreas poderia ser realizada sem conflito com possei ros e sesmeiros e, segundo regulamento de 1854, dever-se-ia começar a demarcação das terras devolutas justamente em tais localidades. Daí porque lamentava M achado Nunes a escolha que fizera a companhia colonizadora. Asterras do Rio Novo localizavam-se em região de antigo povoamento, com posses e sesmaria indígena, enquanto vastas áreas da província eram tidas como devolutas.

Graças à argumentação de M achado N unes, podemos concluir que, do ponto de vista prático, os administradores reconheciam não apenas que muitos índios possuíam títulos legítimos de terras, mas também que as áreas ocupadas por povos indígenas independentes ou, em termos de época, "selvagens", eram definidas como terras vagas e, portanto, devolutas e passíveis de serem destinadas à colonização. As muitas terras devolutas da província do Espírito Santo, referidas por Machado Nunes,nada mais eram do que territórios que ainda estavam sob o domínio das tribos independentes de índios Botocudos e, por isso mesmo, consider adas incontestavel mente "devolutas".

Todo o desenvolvimento subseqü ente dos trabalhos de demarcação de terras devolutas para a venda ou para a localização de núcleos coloniais se fez, realmente, segundo a premissa de que os territórios indígenas, isto é, dos então considerados "selvagens", eram, de fato e de direito, devolutos.Q uanto às terras ocupadas por "índi os civilizados", pelo menos do ponto de vista de certos administradores do período, o fato de esses índios terem recebido sesmariasconstituía obstáculo à ocupação dessas terras por brasilei ros ou imigrantes.

\section{Atos ARBITRÁRIOS E EXPROPRIAÇÃO}

Os direitos patrimoniais de índios incorporados à soci edade brasileira em expansão foram profundamente ignorados e desrespeitados logo após a promulgação da Lei de Terras de 1850. Prevaleceu a idéia de que as “terras de índios", isto é, sesmarias e terras de ald eias, que não estivessem efetivamente ocupadas deveriam ser consideradas devolutas, retornando ao domínio público. A Decisão n. 92 de 21/10/1850, publicada apenas um mês depois da Lei de Terras, fixou essa orientação, que foi rigorosamente seguida até os últimos dias do regime imperial. A decisão mandou incorporar aos próprios nacionais as terras de descendentes de índios que estivessem "confundidos na massa da população civilizada" 25 . Mas parte das chamadas "ter ras de índios" foi objeto de apropriações ilícitas. Também tornou-se comum o aforamento em terras indígenas, segundo formas, al iás,nem sempre consideradas legais. Por isso, ainda se recomendava, na mesma decisão, que apenas se consider assem devolutas as terras que não estivessem ocupadas sob qualquer título que fos- 
se,até que o governo resolvesse sobre a validade ou não daquelas posses e aforamentos em terras indígenas.

Desde a decisão n. 92, o encaminhamento político e administrativo dado às terras indígenas tornou-se arbitrário efreqüentemente nocivo aos interesses e direitos dos índios e de seus descendentes. 0 patrimônio territorial indígena, protegido por títulos legítimos, foi definido por meio de uma nomenclatura imprecisa, sendo ora qualificado como "terras indígenas", ora como "antigas missões ealdeias". Em ambos os casos, entretanto, ignoraram-se as legislações específicas que deram origem àquelas terras.A partir dessa simplificação, a administração imperial começou a produzir "avisos", "decretos" e "leis" sobre tais "terras indígenas", instituindo um poder discricionário que, a rigor, só er a válido em relação às terras reservadas à colonização indígena criadas após a lei de 1850.

O poder arbitrário exercido sobreas terras de índios serviu basicamente para expulsar os índios quetinham títulos legítimos de terras. Depois da decisão 92, foram desativadas diversas al deias em Sergipe, Paraíba, Ceará e Pernambuco, sempre segundo a justificativa de estarem as aldeias abandonadas ou sem reais representantes da po pulação indígena.Em Sergipe chegou-se até mesmo a extinguir-se a Diretoria Geral dos Índios e, para M anuela Carneiro, tal medida foi uma tentativa de demonstração do desaparecimento dos indígenas no local ${ }^{26}$. A resolução oficial sobre o que fazer com as posses e aforamentos em terras indígenas finalmente apareceu em 1860. De acordo com a lei n. 1.114 , de 27 de setembro de 1860, em seu Art. 11, § 8, o governo ficou autorizado a

(... ) aforar ou vender, na conformidade da lei n. 601 de 18 de setembro de 1850, os ter renos pertencentes as antigas M issões e Aldeias dos índios, que estiverem abandonadas, cedendo todavia a parte que julgar suficiente para a cultura dos que nelles ainda permanecerem, e os requererem ${ }^{27}$.

As arbitrariedades da lei de 1860 eram evidentes. Como poderia uma terra indígena estar abandonada e ter, ao mesmo tempo, índios vivendo nela? Pior ainda, com base em qual justificativa legal estava-se interditando aos descendentes dos índios que receberam sesmarias ou terras de aldeia o direito de legitimarem as posses herdadas? As decisões oficiais não enfrentaram e, menos ainda, não elucidaram tais questões, mas permitiram a desativação de grande número de al deias, viabilizando a abertura das terras indígenas à venda e ao aforamento. Aos remanescentes indígenas restava somente a quantidade de terra que alguma autoridade local julgasse suficiente para eles. M as 
tais índios tinham que ser identificados como "índios" para usufruírem o derradeiro direito de posse e propriedade.

A nova conjuntura criada pela Lei de Terras, seu regulamento eleis complementares foram particularmente nocivos ao patrimônio territorial indígena, não apenas porque as decisões oficiais foram arbitrárias e contrárias aos interesses indígenas, mas também porque a nova legislação foi incapaz de coibir as invasões criminosas que continuaram a ocorrer ao arrepio da nova legislação. A continuidade de formação de posses após a promulgação da Lei de Terras era indiscutivelmente um ato criminoso, pois só a compra de terra poderia justificar novas propriedades. M as quando as posses criminosas eram realizadas em terras indígenas, em vez de serem anuladas, serviam antes de motivo para a expropriação dos índios, que passavam a estar "confundidos com a massa da população civilizada".

O contínuo avanço sobre as terras indígenas prevaleceu e mesmo se intensificou depois da Lei de Terras,ameaçando a já frágil situação das comunidades aculturadas ou semi-aculturadas. $M$ achado d'Oliveira, depois de ter percorrido as terras indígenas entre Cabo Frio e Porto Seguro, observou em seu Apontamento sobrea província do Espírito Santo, publicado em 1856, que “(...) as invasões da raça branca, o esquecimento voluntário das leis protetoras, (...) tudo contribuirá a despojá-los [osíndios] inteiramente de suas propriedades..."28. Estava claro para os setores mais lúcidos do período que a expulsão indígena caminhava a passos largos, realizada ao contrário de todas as leis. Isso estava acontecendo com as antigas missões da costa atlântica, mas igualmente nos novos aldeamentos criados no século XIX. O Imperial Affonsino, fundado na década de 1840, estava praticamente extinto por volta de 1858, devido às invasões dos fazendeiros. Em São Paulo a situação não era muito diferente, pois em 1862 foi decretada a extinção de várias aldeias. A resolução oficial n. 29, de 19 de mai o de 1862, autorizava o presidente da província de São Paulo a extinguir aldeamentos,

(... ) distribuindo a cada família no ponto, onde já possua casa e lavoura, bem como aos solteiros maiores de vinte e um annos, que tenham economia separa$\mathrm{da}$, terreno sufficiente que não abranja mais de sessenta e duas mil e quinhentas braças quadradas e seja em geral de vinte e duas mil e quinhentas, que ficarão sendo propriedade desses indivíduos depois de cinco annos de effetiva residência e cultura (... $)^{29}$.

0 aviso n. 29 de 19 de maio de 1862, enviado à província de São Paulo, foi um dentre os muitos que circularam no mesmo período, devotados particularmente ao encaminhamento do processo de liquidação de terras indíge- 
nas, ora originadas em antigas concessões de sesmarias ora em terras reservadas para os mais recentes aldeamentos de índios. Nesse aviso, destaca-se o detalhamento sobre o tamanho das posses que deveriam ser demarcadas para os índios remanescentes, e sobre o caráter condicional à efetiva regularização da situação patrimonial dos índios. A propriedade territorial foi reduzida, desse modo, a pequenos lotes que deveriam ser distribuídos às famílias ou aos futuros "chefes de famílias", representados pelos solteiros, e só seriam efetivamente confirmados após cinco anos.

A distribuição de lotes de dimensões reduzidas era bastante prejudicial aos índios. Eram pequenos e inviabilizavam a mobilidade da agricultura tradicional, que exigia o periódico descanso do solo, apenas conseguido graças à existência de terras disponíveis à rotatividade da lavoura. A lém disso, parte da agricultura indígena era organizada em bases comunitárias e não era, portanto, estritamente familiar. A imposição de pequenos lotes familiares desorganizava não apenas o sistema de trabal ho, mas igualmente as técnicas utilizadas para a produção.

A efetiva regularização da propriedade territorial indígena foi condicionada a uma revisão, após cinco anos, e sua validação estava sujeita ao efetivo cultivo e moradia no local. Tais condições não tinham precedentes nem o me nor apoio na nova legislação ter ritorial promulgada em 1850, e apenas confirmavam, mais uma vez, as arbitrariedades praticadas largamente contra os índios que possuíam títulos legítimos de terras. Razões que justificassem as condições impostas à regularização da propriedade indígena não foram apresentadas, embora pudessem estar subjacentes pelo menos duas expectativas: a de que em cinco anos o número de índios no local seria, senão inexistente, certamente menor; ou que as invasões a terras indígenas iriam continuar, devendo o Estado estar preparado para agir discricionariamente a fim de solucionar o problema.

Em outras palavras, o caráter condicional dos lotes reservados aos remanescentes indígenas demonstra que a administração imperial parecia acreditar ou na extinção física dos índios ou que, se na melhor das hipóteses eles sobrevivessem, seria na condição de trabalhadores sem terra. D efato, a possibilidade de os índios manterem o domínio sobre os lotes era mínima, não apenas porque as condições de produção e de trabalho tinham sido repentinamente modificadas, mas também porque dificilmente el es poderiam fazer face às invasões que caracterizavam as regiões expostas à expansão da fronteira agrícola.

As leis e avisos complementares à Lei de Terras de 1850 praticamente fecharam todas as al ternativas à propriedade indígena. As terras pertencentes às tribos independentes, embora não pudessem ser consideradas devolutas, 
foram efetivamente tratadas como terras do domínio público, sob a al egação de que estariam "vagas", isto é, não teriam o domínio ou posse de pessoa alguma. Para sanar a incongruência desse raciocínio, os legisladores se limitaram a reservar parte das terras devolutas à "colonização indígena". As terras indígenas oriundas de antigas sesmarias ou aldeias sem cultura e moradia efetiva foram igualmente consideradas vagas e, por isso, deveriam retornar ao domínio das terras públicas. M uitas aldeias e missões foram sumariamente extintas, e a última possi bilidade ainda existente aos índios remanescentes em sesmarias e terras de aldeia era a de possuírem pequenos lotes de terra.

Mas,para os índios permanecerem na pouca terra que lhes restava seria necessário, primeiro, que fossem reconhecidos como "índios". I sso os colocava na dependência das autoridades locais que, afinal,arbitravam sobre serem ou não os índios "verdadeiros índios". Q ue muitos índios foram desde então considerados "não índios" e despojados de suas terras, não restam muitas dúvidas, como atestam os inúmeros casos de desativação de antigas missões e aldeias. 0 aviso n. 29, de 19 de maio de 1862, que autorizou a extinção de várias aldeias de São Paulo, por exemplo, justificou a medida justamente afirmando que à

(... ) vista das informações offerecidas pelo Director Geral de Índios dessa Província, convenceu-se o Governo Imperial de que ahi existem muitos aldeamentos formados de in divíduos, que, pela mór parte,somen te de Índios tem o nome $(\ldots)^{30}$.

Com a Lei de Terra, multiplicaram-se, portanto, os "caboclos" sem terra. Isto é, uma população tida como mestiça, de origem nacional, bastante pobre e dependente dos grandes proprietários rurais, mas sem nenhum direito formal sobre as terras que ocupava. Ademais, um novo problema foi erigido aos membros das comunidades indígenas: provarem, a contragosto da sociedade regional onde estavam inseridos, serem "índios de verdade", com direitos legais sobre seus assentamentos.

\section{NOTAS}

${ }^{1} \mathrm{~A}$ pesquisa da qual se originou este artigo contou com o apoio do CN Pq, uma entidade do governo brasileiro voltada ao desenvolvimento científico e tecnológico.

${ }^{2}$ Conferência dos Povos Indígenas. Documento final. In Projeto Brasil Outros 500, http://www.brasil-outros 500.org.br/, [26/7/2000]. 
${ }^{3}$ OLIVEIRA, J oão Pacheco de. Os Caxixós do Capão do Zazinho: uma comunidade indígena distante de imagens da primitividadee do índi o genérico. Relatório encaminhado à FUNAI - Fundação Nacional do Índio, em cumprimento do contrato de consultoria DGEP 30/2000. Rio de Janeiro: M useu Nacional/UFRJ, 16 de julho de 2001, passim.SI LVA, Sandro José da. "Ajustando quais condutas? Tempo e espaço entre os tupiniquins" . In M osaico. Vitória, Ano 1, vol. 1, no1, p. 308.

${ }^{4}$ Apud. MEN DES JÚN IOR, João. O s indígenas do Brazil, seus direitos, individuais e políticos. São Paulo: Typ. Hennies Irmãos, 1921, pp. 34-35.

${ }^{5}$ SAIN T-HILAIRE, Auguste. Viagem ao Espírito Santo e Rio Doce. São Paulo/Belo Horizonte: EDUSP/Itatiaia, 1974, pp. 31-32.

${ }^{6}$ Idem, p. 32.

${ }^{7}$ Idem, p.65.

${ }^{8}$ Idem, pp. 68-69.

${ }^{9}$ M ARQUES, C ezar Augusto. Dicionário histórico, geográfico e estatístico da província do Espírito Santo. Rio de Janeiro: Typographia Nacional, 1878, pp. 8-9.

${ }^{10}$ Decreto n. 102 de 5/5/1824. In CUN HA, Manuela Carneiro da (org). Legislação indigenista no século XIX. U ma compilação. São Paulo: EDUSP, 1992, p. 116.

${ }^{11}$ SILVA, Lígia O sório. "A 'questão da terra' e a formação da sociedade nacional". In Anais do II Congresso Brasileiro deH istória Econômica. Niterói, 13 a 16 de out. de 1996, v. I, pp. 35-51, p. 38.

${ }^{12}$ Idem, p. 169.

${ }^{13}$ Idem, p. 35.

${ }^{14}$ A pud. SI LVA, Lígia O sório. Terras devolutas e latifúndio. Campinas: Ed. da Unicamp, 1996, pp. 156-157.

${ }^{15}$ Sobre a discussão ver SI LVA Lígia Osório. Op. cit., pp. 157-161.

${ }^{16}$ Idem, p. 161.

${ }^{17}$ Cf. Legislação em VASCON CELLOS, J. M . P. de. Livro das terras ou coleção da Lè, Regulamentos e ordens. 4 ed. Rio de Janeiro: H. Lammert \& C., 1885, p. 15.

${ }^{18}$ MENDES JÚNIOR, op. cit., p. 58.

${ }^{19}$ Idem, p. 59.

${ }^{20} \mathrm{Idem}, \mathrm{p} .32$.

${ }^{21}$ CUNHA, M anuela Carneiro da. Política indigenista no século XIX. In CUNHA, Manuela Carneiro da (org). História dosíndi os no Brasil. São Paulo: Companhia das Letras: Se cretaria Municipal de Cultura: FAPESP, 1992, pp. 133-154, pp. 141-142. 
${ }^{22}$ ESPÍRITO SANTO. Relatório Provincial. 1855, s/p.

${ }^{23}$ SI LVA, Lígia Osório. Op. cit., p. 168.

${ }^{24}$ Idem, p. 168.

${ }^{25}$ CUN N A, M anuela Carneiro da. Legislação. Op. cit., p. 214.

${ }^{26}$ Idem, p. 15.

${ }^{27}$ Lei no 1.114 de 27/9/1860. In: CU N H A, M anuela Carneiro da. . O p. cit., p. 257.

${ }^{28}$ D'OLIVEIRA, Machado. "A pontamentos sobre a província do Espírito Santo". In Revista do Instituto Histórico e Geográfico do Brasil. Rio de Janeiro, T. XIX n n.22, pp. 161-348, 2은 trim. 1856, p. 256.

${ }^{29} \mathrm{Cf}$. M anuela Carneiro da Cunha, . O p. cit., p. 259.

${ }^{30}$ Idem, p. 258. 